\title{
Effects of Carbon Fiber Treatment on Interfacial Properties of Advanced Thermoplastic Composites
}

\author{
Gwomei Wu \\ Department of Chemical Engineering, Chang Gung College of Medicine and Technology, \\ Kweisan, Taoyuan, Taiwan, Republic of China
}

(Received November 8, 1996)

\begin{abstract}
The surface free energy and composition of carbon fibers showed strong correlation with treatment history. In this report, untreated AU, surface-treated AS, and heat-treated (under vacuum) ASH carbon fibers were used in poly(ether ether ketone) (PEEK) and poly(ether sulphone) (PES) composite systems. The relationships between treatment of carbon fibers (thus surface characteristics of carbon fibers) and interfacial properties of advanced thermoplastic composites were investigated. Both single-fiber-composite samples and prepreg-made composite laminates were used. The interfacial shear strength was doubled in PEEK matrix and increased $16 \%$ in PES matrix, as revealed by single-fiber-composite. PES composite laminates showed improvement of $20 \%$ and $26 \%$ in TFS and SBSS, respectively, when changed from AU to AS fiber systems. The heat treatment reduced the surface free energy of carbon fiber by removing these functional group elements and reduced adhesion. In addition, the effects of carbon fiber surface composition are discussed.
\end{abstract}

KEY WORDS Carbon Fiber/Treatment/Interfacial Property / Composite / Single Fiber Composite /

Carbon fiber reinforced thermoplastic composites have excellent mechanical properties and design flexibility. The necessity to reduce weight in high performance applications has led to rapid rise in the use of structural composite materials. However, the efficiency of utilizing the strength and stiffness of reinforcement fibers is essentially dependent upon the degree of adhesion between fibers and matrix material.

Oxidative surface treatment improves adhesion. Improved adhesion is generally caused by chemical interactions between carbon fiber surface oxides and reactive groups of the matrix materials. ${ }^{1}$ The effects of oxidative surface treatment and further heat treatment under vacuum of carbon fibers has been analyzed and quantified. ${ }^{2}$ The surface free energy and surface composition of carbon fibers showed strong correlation with treatment history. Oxidation increased the surface free energy of carbon fiber by introducing functional group elements (oxygen and nitrogen). Further heat treatment under vacuum reduced the surface free energy by removing added elements from the surface of carbon fibers.

In this study, untreated AU, surface-treated AS (Hercules, U.S.A.), and surface-treated carbon fibers with further heat treatment (ASH) were used in poly(ether ether ketone) (PEEK) and poly(ether sulphone) (PES) composite systems. The relationships between treatment of carbon fibers (surface characteristics of carbon fibers) and the interfacial properties of advanced thermoplastic composites were investigated. Single-fiber-composite samples and unidirectional composite laminates have been studied. The effects of carbon fiber surface compositions (quantified by X-ray photoelectron spectroscopy) on fiber/matrix adhesion are discussed.

\section{EXPERIMENTAL}

Polyacrylonitrile based carbon fibers were used. Untreated AU and surface-treated AS fibers were supplied by Hercules, U.S.A. ASH fibers were prepared by further heat-treating AS fibers under vacuum $\left(<10^{-7}\right.$ Torr) to the designated temperature (i.e., 300 , 500,700 , and $1000^{\circ} \mathrm{C}$ ) at a constant heating rate of $20^{\circ} \mathrm{Cmin}^{-1}$. The samples were then allowed to cool to room temperature with the initial cooling rate at $40^{\circ} \mathrm{Cmin}^{-1}$.

Two methods are commonly used to study the shear strength of an interface in composites: (1) the fiber pullout method and (2) single-fiber-composite method. ${ }^{3-5}$ The fiber pull-out technique is useful with glass fibers, but is much more difficult to use with more brittle and much smaller carbon fibers.

The single-fiber-composite technique is a straightforward experimental procedure. One 1-cm-long carbon fiber is embedded in a tensile dogbone coupon of matrix polymer. The coupon is subjected to tensile loading. Tensile stress is then transferred to the fiber through the shear stress at the fiber-matrix interface.

The geometries of the single-fiber-composite specimens used are sketched in Figure 1. The corresponding stress distribution along the fibers during testing is shown in Figure 2. Since the maximum strain of the brittle carbon fiber is much lower than that of the polymer, the fiber fractures into small fragments within the matrix. This fracture continues until the interfacial stress no longer induces further fracture of carbon fiber. The fiber length that survives is called the critical fiber length $L_{\mathrm{c}}$. Based on the force balance in a micromechanical model, Kelly and Tyson ${ }^{6,7}$ proposed that

$$
\tau=\frac{\sigma_{\mathrm{f}}^{d}}{2 L_{\mathrm{c}}}
$$

where $\tau$ is the interfacial shear strength, $\sigma_{\mathrm{f}}$ is the fiber failure stress at the critical fiber length $L_{\mathrm{c}}$, and $d$ is the diameter of the fiber. $L_{\mathrm{c}} / d$ is also called the critical aspect ratio. The actual fragment length varies between $L_{\mathrm{c}} / 2$ and $L_{\mathrm{c}}$, with a mean of $3 / 4 L_{\mathrm{c}} \cdot{ }^{8}$ The equation assumes a uniform strength along the fiber. However, this is generally not true for the strong and brittle carbon fibers because of the flaws in the material. 


\section{RESULTS AND DISCUSSION}

\section{$L_{\mathrm{c}}$ in PEEK Matrix}

Untreated AU, surface-treated AS and heat-treated ASH carbon fibers were used to make single-fibercomposite specimens. One 1-cm-long carbon fiber was centered inside each $100 \mathrm{~mm} \times 25 \mathrm{~mm} \times 0.16 \mathrm{~mm}$ PEEK matrix sample by compression molding.

PEEK powders (150P from ICI, UK) were sieved before use. Particle size was controlled to less than 250 $\mu \mathrm{m}$ to avoid air bubbles. The fiber/PEEK assembly was melted at $400^{\circ} \mathrm{C}$ without applying significant pressure for $3 \mathrm{~min}$. After PEEK was melted in the press, the molding pressure was gradually increased up to $3 \mathrm{MPa}$ for 20 seconds. The whole assembly was then immediately transferred to a pneumatically controlled cold press. The cold press removed the heat and allowed the $1-\mathrm{cm}$-long carbon fiber to be embedded in a solidified PEEK matrix.

Due to the fast cooling rate during solidification in the pneumatically controlled cold press, PEEK became amorphous and transparent. The specimens were then cut to the sizes specified in Figure 1, using a steel rule die.

The dogbone tensile coupons were pulled by a mechanical tester at a crosshead speed of $1.3 \mathrm{~mm} \mathrm{~min}^{-1}$ at room temperature. Each test was stopped when elongation of the specimen exceeded $20 \%$ the original length. To observe fiber fragments within the matrix, the specimen had to be either heat-remelted or solventdissolved to allow the fiber fragments to be separated by flow. Consequently, each tested specimen was dissolved in sulfuric acid. To prepare the sample for examination under microscope, dissolving was performed on a glass slide. The acid was carefully dropped onto the PEEK sample. Gentle heating was necessary at this stage to
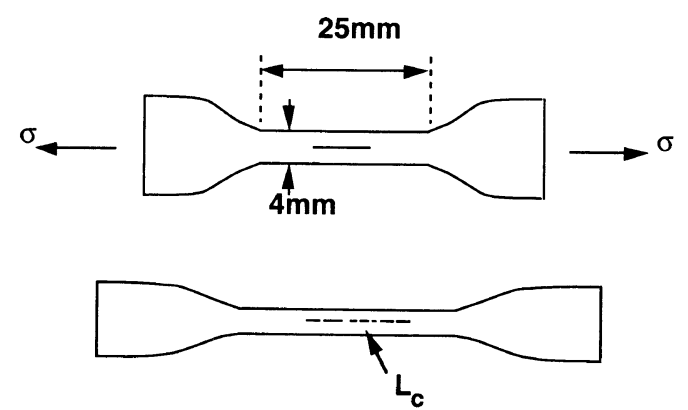

Figure 1. Single-fiber-composie specimen geometry.

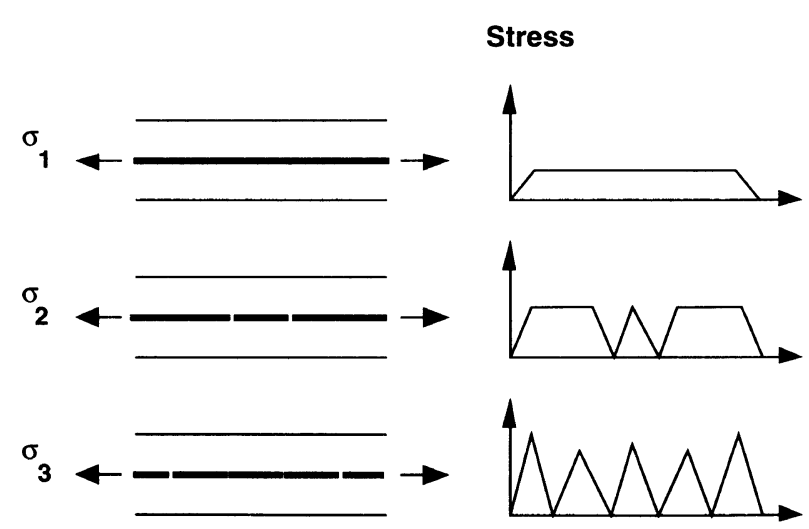

Figure 2. Corresponding stress distribution along a fiber during testing $\left(\sigma_{1}<\sigma_{2}<\sigma_{3}\right)$. ensure dissolution of the PEEK matrix. The glass slides were then examined under a microscope.

The averaged critical fiber length $L_{\mathrm{c}}$ and critical aspect ratio $L_{\mathrm{c}} / d$ of each group of carbon fibers in PEEK matrix are listed in Table I. Data are the results of three to six specimens. Fifty to one hundred fiber fragments were collected per specimen. The surface free energies of the fibers as revealed using a Cahn dynamic contact angle system were included for comparison. The critical aspect ratio of AS carbon fibers in PEEK matrix was almost one half that of AU carbon fibers, indicating 100\% improvement in the interfacial shear strength between the PEEK matrix and carbon fibers. This suggests a dominant role of fiber surface energetics on the interfacial shear strength in PEEK composites. The results of ASH fibers were generally similar to those of AU fibers.

It was noted that standard deviations in Table I were as high as $20-50 \%$ of the measured $L_{\mathrm{c}}$. However, this testing should give fiber fragment lengths of $(3 / 4 \pm 1 / 4) L_{\mathrm{c}}$ or $\left(3 / 4 L_{\mathrm{c}}\right) \pm 33 \%$. Therefore, high standard deviations were expected and the testing results were used for comparison only.

\section{$L_{\mathrm{c}}$ in PES Matrix}

Single-fiber-composite specimens were prepared from PES (3600P from ICI, UK). Fine, sieved powders of PES were used. Particle size was less than $500 \mu \mathrm{m}$. The molding procedure was similar to the one for PEEK samples, except PES was heated at $380^{\circ} \mathrm{C}$.

PES single-fiber-composites were pulled under tension at $1.3 \mathrm{~mm} \mathrm{~min}^{-1}$ at room temperature until failure. To observe the fiber fragments within the PES matrix, the tested specimens were dissolved on a glass slide using cyclopentanone. Gentle heating was used. After the solvent was evaporated, a thin layer of PES was deposited on the glass slide and became ready for examination.

The results of averaged critical fiber length and critical aspect ratio of each group of carbon fibers in PES matrix are shown in Table II along with fiber surface free energy data. About fifteen fiber fragments were counted for each group. There was a $16 \%$ decrease in the critical aspect ratio from AU to AS fibers. This suggests a $16 \%$ increase

Table I. Critical length of carbon fiber in PEEK mattrix system ${ }^{a}$

\begin{tabular}{lccccc}
\hline \multicolumn{1}{c}{ Sample } & AS & ASH300 & ASH500 & ASH1000 & AU \\
\hline$\underline{L_{\mathrm{c}}} / \mathrm{mm}$ & 0.250 & 0.471 & 0.470 & 0.480 & 0.484 \\
& $(0.150)$ & $(0.199)$ & $(0.276)$ & $(0.240)$ & $(0.227)$ \\
$L_{\mathrm{c}} / d$ & 36 & 67 & 67 & 69 & 69 \\
$\begin{array}{l}\text { Surface free } \\
\text { energy/dyn cm }\end{array}$ & 49.8 & 46.0 & 45.4 & 33.0 & 31.5 \\
\hline
\end{tabular}

${ }^{a}$ Standard deviation shown in parentheses.

Table II. Critical length of carbon fiber in PES matrix system ${ }^{\mathrm{a}}$

\begin{tabular}{|c|c|c|c|c|c|}
\hline Sample & AS & ASH300 & ASH700 & ASH 1000 & AU \\
\hline$\underline{L_{\mathrm{c}}} / \mathrm{mm}$ & $\begin{array}{c}0.439 \\
(0.113)\end{array}$ & $\begin{array}{c}0.433 \\
(0.223)\end{array}$ & $\begin{array}{c}0.531 \\
(0.313)\end{array}$ & $\begin{array}{c}0.532 \\
(0.170)\end{array}$ & $\begin{array}{c}0.512 \\
(0.128)\end{array}$ \\
\hline$L_{\mathrm{c}} / d$ & 63 & 62 & 76 & 76 & 73 \\
\hline $\begin{array}{l}\text { Surface free } \\
\text { energy } / \mathrm{dyn}^{-1}\end{array}$ & 49.8 & 46.0 & 31.7 & 33.0 & 31.5 \\
\hline
\end{tabular}

${ }^{\text {a }}$ Standard deviation shown in parentheses. 
in the interfacial shear strength while the fiber failure stress is assumed to be more or less identical within the same matrix system. As with PEEK matrix, the results of ASH fibers in the PES matrix were very close to those of $\mathrm{AU}$ fibers, except that ASH300 (heat-treated up to $300^{\circ} \mathrm{C}$ ) showed behavior similar to AS fibers. The heat treatment of carbon fibers seemed to remove the active surface oxides, thus greatly reducing the interaction between carbon fiber surface and PES matrix.

\section{PES Composite Laminates}

Some PES composite prepregs of $68 \%$ by weight of fiber were prepared from carbon fibers, using a solution impregnation technique. ${ }^{9}$ The prepregs were dried and layed up for compression molding according to the following procedure. All samples were held at $350^{\circ} \mathrm{C}$ for $15 \mathrm{~min}$ under zero pressure to eliminate residual solvent and then pressed for $5 \mathrm{~min}$ at $3 \mathrm{MPa}$ before cooling under pressure. The initial cooling rate was about $10^{\circ} \mathrm{Cmin}^{-1}$.

Unidirectional composite panels of 12 plies were prepared for transverse flexural tests. The short-beam shear strength (SBSS) was measured on 24-ply unidirectional samples. Table III summarized the results of transverse flexural modulus (TFM), transverse flexural strength (TFS), and SBSS of PES composite laminates. Data represent average results of five or more specimens. Here, PES composites made from AS carbon fibers showed distinct mechanical properties compared with samples made from AU carbon fibers. TFS increased $20 \%$, and SBSS improved $26 \%$. The effects of surface treatment of carbon fibers on interfacial properties of PES composite were quantified. The results of TFM were essentially the same because of moduli of reinforcing carbon fibers. TFM was therefore not a sensitive means for assessing fiber-matrix adhesion in composites.

The effects of heat treatment of carbon fibers on the interfacial properties of PES composites were more difficult to define. The heat treatment under vacuum removed varying amounts of oxygen and nitrogen elements from the carbon fiber surface. This simultaneously reduced the surface free energy of carbon fibers. A single-fiber-composite study showed decrease in the interfacial shear strength of carbon fibers in PEEK and PES matrices because of the heat treatment. However, there seems a maximum in the results of TFS around the heat treatment temperature of $500^{\circ} \mathrm{C}$ in Table III. An independent study by X-ray photoelectron spectroscopy (XPS or ESCA) showed similar sodium concen-

Table III. Mechanical properties of PES composite laminates ${ }^{a}$

\begin{tabular}{lccc}
\hline Carbon fiber & $\begin{array}{c}\text { Transverse } \\
\text { flexural } \\
\text { modulus/GPa }\end{array}$ & $\begin{array}{c}\text { Transverse } \\
\text { flexural } \\
\text { strength/MPa }\end{array}$ & $\begin{array}{c}\text { Short-beam } \\
\text { shear } \\
\text { strength/MPa }\end{array}$ \\
\hline AS & $8(0.5)$ & $48(4)$ & $72(1)$ \\
ASH300 & $8(0.5)$ & $45(5)$ & - \\
ASH500 & $9(0.5)$ & $63(5)$ & - \\
ASH700 & $7(0.5)$ & $55(5)$ & - \\
ASH1000 & $7(0.5)$ & $40(5)$ & - \\
AU & $7(0.2)$ & $40(3)$ & $57(2)$ \\
\hline
\end{tabular}

${ }^{\text {a }}$ Standard deviation shown in parentheses. tration. ${ }^{2}$ Alkaline salt additives result in postpolymerization or crosslinking of aromatic polymers, ${ }^{10}$ such as PES and PEEK. The variation in surface sodium concentration due to heat treatment might have affected the molecular weight distribution of the PES matrix near carbon fiber surfaces. PES prepregs were made using PES in cyclopentanone solution. The molecule segregation might be faster in such a solution system, ${ }^{11}$ and complicate the system. These all influence the interactions between carbon fiber surface elements and PES matrix molecules, and thus the performance of composite systems.

\section{CONCLUSIONS}

Optimum fiber-matrix adhesion was necessary for good transfer of fiber properties and full utilization of matrix toughness in carbon-fiber-reinforced thermoplastic composites. Oxidative surface treatment increased the surface free energy of carbon fiber by introducing functional group elements and improved the adhesion between fiber and thermoplastic matrices. The interfacial shear strength was doubled in PEEK matrix and increased $16 \%$ in the PES matrix, as revealed by single-fiber-composite testing. PES composite laminates showed improvement of $20 \%$ and $26 \%$ in TFS and SBSS, respectively, when changed from AU to AS fiber systems. Heat treatment reduced the surface free energy of carbon fiber by removing functional group elements. The adhesion between fiber and thermoplastic matrices was thus reduced. In the single-fiber-composite study, the interfacial shear strength of ASH fiber system decreased to that of the AU fiber system. However, the transverse flexual strength of PES composite laminate showed variation with the surface sodium concentration of carbon fiber. The surface sodium may induce postpolymerization or crosslinking of the PES matrix and influence the performance of composite material systems.

Acknowledgment. This work was partially supported by the National Science Council (ROC) under No. NSC85-2216-E182-001.

\section{REFERENCES}

1. E. Fitzer and R. Weiss, Carbon, 25, 455 (1987)

2. G. M. Wu, J. M. Schultz, D. J. Hodge, and F. N. Cogswell, Polym. Comp., 16, 284 (1995).

3. A. N. Netravali, R. B. Henstenburg, S. L. Phoenix, and P. Schwartz, Polym. Comp., 10, 226 (1989).

4. R. B. Henstenburg and S. L. Phoenix, Polym. Comp., 10, 389 (1989).

5. A. N. Netravali, P. Schwartz, and S. L. Phoenix, Polym. Comp., 10, 385 (1989).

6. A. Kelly and W. R. Tyson, J. Mech. Phys. Solids, 13, 329 (1965).

7. A. Kelly, Proc. R. Soc. London, Ser. A, 319, 95 (1970).

8. A. S. Wimolkiatisak and J. P. Bell, Polym. Comp., 10, 162 (1989).

9. G. M. Wu, J. M. Schultz, D. J. Hodge, and F. N. Cogswell, Proceedings of Annual Technical Conference (ANTEC) in Dallas, Texas, The Society of Plastics Engineers (SPE), Brookfield, Connecticut, 1990, p 1390.

10. M. V. Ward and E. Nield (ICI), US Patent No. 4722980 (1988).

11. A. Pangelinan and R. L. McCullough, presented at The American Chemical Society Annual Meeting, Boston, 1990. 